\title{
The Severity of Changes in Cardiovascular Risk Factors in Adults Over a Five-Year Interval
}

This article was published in the following Dove Press journal:

Clinical Interventions in Aging

\author{
Anita Liput-Sikora (D) \\ Anna Maria Cybulska $\mathbb{D}^{2}$ \\ Wiesława Fabian' \\ Marzanna Stanisławska (D) ${ }^{2}$ \\ Magdalena Sylwia Kamińska (iD ${ }^{3}$ \\ Elżbieta Grochans iD ${ }^{2}$ \\ Anna Jurczak (iD) 4 \\ 'Primary Care Center (NZOZ \\ Przychodnia Medycyny Rodzinnej SJ), \\ Szczecin 7I-52I, Poland; ${ }^{2}$ Department of \\ Nursing, Faculty of Health Sciences, \\ Pomeranian Medical University in \\ Szczecin, Szczecin 7I-210, Poland; \\ ${ }^{3}$ Subdepartment of Long-Term Care, \\ Department of Social Medicine, Faculty of \\ Health Sciences, Pomeranian Medical \\ University in Szczecin, Szczecin 7I-210, \\ Poland; ${ }^{4}$ Department of Specialized \\ Nursing, Faculty of Health Sciences, \\ Pomeranian Medical University in \\ Szczecin, Szczecin 7I-210, Poland
}

Correspondence: Anna Maria Cybulska Pomeranian Medical University in Szczecin, Faculty of Health Sciences, Żołnierska 48, Szczecin 7I-210, Poland Tel +48 9l 4800910

$\mathrm{Fax}+48914800905$

Email anna.cybulska@pum.edu.pl
Purpose: The aim of this study was to analyze the severity of changes in cardiovascular risk factors (hypertension, overweight and obesity, carbohydrate metabolism disorders, burdened family history) and to assess the risk of a cardiovascular incident according to the Systematic Coronary Risk Evaluation (SCORE) algorithm in the same group of patients over a five-year interval.

Patients and Methods: The research method was analysis of medical records of patients from the area of West Pomeranian Province, Poland, included in the Cardiovascular Disease Prevention Program of the National Health Fund five years after the first examination (2012/ 2013 vs 2017/2018). We collected data on changes in the levels of selected cardiovascular risk factors over five years and calculated the SCORE values.

Results: In the second measurement (after five years), the odds of obesity were about 2.5 times higher. The repeated BMI measurement showed that after five years more respondents were classified as overweight and obese compared with the first measurement $\left(p=0.000 ; \eta^{2}\right.$ $=0.056)$. The repeated SCORE measurement indicated that after five years the SCORE values significantly increased compared with the first measurement $\left(p=0.000 ; \eta^{2}=0.588\right)$. Statistically significant differences $(p<0.05)$ were also found between the first and the second measurements of arm circumference, waist circumference, BMI, diastolic blood pressure, heart rate, and triglycerides. The risk of visceral obesity was statistically significantly higher for men than for women $\left(\mathrm{R}_{\mathrm{HM}}=1.47\right)$.

Conclusion: In the group of patients examined twice over five years, the incidence of obesity, including abdominal obesity, significantly increased. Furthermore, five years after the last examination, the risk of a cardiovascular incident significantly increased. The participants had higher values of such parameters as: arm circumference, waist circumference, BMI, diastolic blood pressure, heart rate, and triglycerides.

Keywords: cardiovascular disease, risk factors, prevention, SCORE

\section{Introduction}

Cardiovascular disease (CVD) is the leading cause of death in Poland and worldwide. Cardiovascular mortality in Poland is one of the highest in Europe. Epidemiological and socio-medical studies show that some behavioral patterns that make up the modern lifestyle play an important role in the development of cardiovascular disease. The most important risk factors include hypertension, dyslipidemia, nicotinism, overweight and obesity, carbohydrate metabolism disorders, low physical activity, and family history of early-onset cardiovascular disease. ${ }^{1}$

The determination of overall cardiovascular risk is the basis for taking correct decisions on the implementation of cardiovascular disease prevention and treatment 
programs. The European Society of Cardiology (ESC) recommends using the Systematic Coronary Risk Evaluation (SCORE) for risk assessment. It is a system of tables that can be used to assess the risk of cardiovascular death within 10 years, taking into account age, sex, the level of total cholesterol (TC), systolic blood pressure, and smoking. This algorithm is intended for use in primary prevention. According to the ESC recommendations, people with documented cardiovascular disease or after a cardiovascular event are in the high-risk group. ${ }^{2,3}$

Two versions of the SCORE tables were developed for the European population - for low- and high-risk countries. The standardized cardiovascular disease and diabetes mortality rate for the population of 45-74-year-olds decide to which category a country should be assigned. Its values for low-risk countries are $<160 / 100.000$ for women and $<220 / 100.000$ for men. According to these categories, Poland has been classified as a high-risk country. Since 2007, the SCORE has been performed using tables calibrated for the Polish population. These tables were created based on the results of the NATPOL III (abbreviation of the Polish title Nadciśnienie Tętnicze w Polsce [Arterial Hypertension in Poland]) survey from 2002, in which the standardized mortality rate was $413.9 / 100.000$. It decreased by $23.2 \%$ and amounted to $317.8 / 100.000$ in 2011. It has been shown that the system of tables calibrated for Poles used since 2007 significantly overestimated the SCORE values compared to the tables prepared by ESC experts. ${ }^{4,5}$

The Cardiovascular Disease Prevention Program was designed and launched in 2002 in Łódź, Poland as a pilot program. On July 1st, 2004 the National Health Fund (Polish abbreviation NFZ, Narodowy Fundusz Zdrowia) implemented this Program in the whole Poland.

The Cardiovascular Disease Prevention Program is a screening program, based on the decision of a President of the National Health Fund on the terms of concluding and implementing contracts such as preventive health programs, and on the basis of the Act of 27 August 2004 on health care services financed from public funds. Research under the Program includes as follows: 1 . Interview and physical examination (anthropometric measurements, determination of the body mass index (BMI) value, and blood pressure measurement); 2. Blood chemistry tests (total cholesterol (TC), LDLcholesterol (LDL-C), HDL-cholesterol (HDL-C), triglycerides (TG) and glucose levels in the blood); 3. Entering the test results into the "Preventive Examination Card"; estimation of the global risk of a future cardiovascular event according to the
SCORE algorithm, and qualification of the patient to the appropriate risk group; health education of the patient and making decisions about the further management of the patient.

The criteria for the recruitment of participants for the Cardiovascular Disease Prevention Program were: no diagnosis of cardiovascular disease, not using services provided as part of the prevention of cardiovascular diseases during the previous five years, having the following risk factors: arterial hypertension (blood pressure values over 140/90 mmHg), high blood levels of TC, LDL-C, and TG, and low levels of HDL-C, smoking, low physical activity, overweight and obesity, impaired glucose tolerance, increase in fibrinogen concentration, increase in uric acid levels, excessive stress, irrational nutrition, genetic load, age of $35,40,45$ or 55 years; submission of a declaration of selection of a primary care physician.

The main goal of the Cardiovascular Disease Prevention Program is to reduce the morbidity and premature mortality due to cardiovascular diseases in the Polish population included in the Program, through early detection and reduction of cardiovascular risk factors. This Program is also to increase the detection of cardiovascular diseases and improve the effectiveness of treatment, early identify people with an increased risk of cardiovascular disease, and promote a healthy lifestyle (non-smoking, proper nutrition, and physical activity).

The aim of this study was to analyze the severity of changes in cardiovascular disease risk factors (hypertension, overweight and obesity, carbohydrate metabolism disorders, burdened family history) and to assess the risk of a cardiovascular incident according to the SCORE algorithm in the same group of patients over a five-year interval.

\section{Patients and Methods}

\section{Study Group}

As part of the Cardiovascular Disease Prevention Program financed by the National Health Fund, we analyzed 294 patients of the outpatient clinic in Szczecin, West Pomeranian Province, Poland. Recruitment was carried out using leaflets, invitations and information provided at the outpatient clinic.

The inclusion criteria were: place of residence in West Pomeranian Province, Poland, participation in both parts of the Program (in 2012/2013 for the first time, and in 2017/2018 for the second time), and the age of 35, 40, 45, 50 , or 55 years. The exclusion criteria were: an early 
diagnosis of cardiovascular disease, and using services provided as part of the Program by any other medical centers during the last five years, according to the decision of a President of the National Health Fund on determining the conditions for concluding and implementing contracts such as preventive health programs, and on the basis of the Act of 27 August 2004 on health care services financed from public funds.

The study was conducted using the "Preventive Examination Card" in accordance with the instructions published by the National Health Fund. What is more, medical documents of the patients included in the study were analyzed.

All participants gave informed consent for inclusion before participating in the study. The study was conducted in accordance with the Declaration of Helsinki, and the study was approved by the Bioethics Committee of the Pomeranian Medical University, Szczecin, Poland.

\section{Procedure}

An identical procedure was adopted in both studies: the first performed in 2012/2013 and the second conducted in 2017/2018. It involved as follows: 1. Interview and physical examination (anthropometric measurements (weight $[\mathrm{kg}]$, height $[\mathrm{cm}]$, arm and waist circumference $[\mathrm{cm}]$ ) and blood pressure measurement); 2. Blood sampling; 3. Estimation of the global risk of a future cardiovascular event according to the SCORE algorithm.

\section{Interview and Physical Examination}

At the first stage of the study the interview was performed in order to collect sociodemographic and general data on cardiovascular risk factors such as hypertension, burdened family history, low physical activity, and smoking.

\section{Anthropometric Measurements}

Weight $[\mathrm{kg}]$ and height $[\mathrm{cm}]$ was measured and rounded to the nearest $0.1 \mathrm{~kg}$ and $0.1 \mathrm{~cm}$. A medical scale with an integrated measuring rod (SECA 711) was used, and a standard procedure was followed. Additionally, arm $[\mathrm{cm}]$ and waist circumference $[\mathrm{cm}]$ for each patient was measured. The arm circumference was taken at the midpoint between the bony protrusion on the shoulder (acromion) and the point of the elbow (olecranon process). The waist circumference was taken when the participant was standing upright with feet slightly apart and arms hanging loosely to the side. The measurement was taken at the end of a normal expiration as the position of the diaphragm could influence the accuracy of the measurement. The measurement was started at the top of your hip bone, and then we brought the tape measure all the way around your body, level with your belly button. Measurements are recorded to the nearest $0.1 \mathrm{~cm}$.

\section{Blood Pressure Measurement}

Blood pressure was measured twice using a sphygmomanometer in accordance with the guidelines of the Polish Society of Hypertension. ${ }^{6}$ The measurement was taken after a 30-minute rest, using a cuff fitted to the size of the patient's arm. The patients were sitting with back support, the bare upper limb, and the cuff placed at the height of the patient's heart. The patients did not consume coffee and did not smoke before the examination. Blood pressure was expressed in millimeters of mercury (mmHg). ${ }^{6}$ After measuring blood pressure, heart rate was assessed. The number of heartbeats was measured for a minute.

\section{Sampling Analysis}

At the second stage of the study, whole blood was taken using the Vacutainer method. There was a 12-hour interval between blood collection and the last meal. Blood samples were taken at the blood collection point at 7.30-10.30. The plasma levels of glucose, TC, LDL-C, HDL-C, and TG were measured.

\section{The SCORE Algorithm}

The third stage of the study involved entering the data (anthropometric measurements, blood pressure measurement, and blood parameters) into the National Health Fund Prevention Monitoring System. In accordance with the Program guidelines, the patients' BMI according to the formula: $\mathrm{BMI}=$ weight $[\mathrm{kg}]$ : height ${ }^{2}\left[\mathrm{~m}^{2}\right]$ was calculated and the risk of death due to acute cardiovascular events in ten years was estimated according to the SCORE algorithm.

The following standard values were adopted: ${ }^{7}$

- Blood pressure: normal blood pressure (systolic blood pressure (SBP) $<140 \mathrm{mmHg}$ and diastolic blood pressure (DBP) $<90 \mathrm{mmHg}$ ), and hypertension: blood pressure in two independent measurements: SBP $\geq 140 \mathrm{mmHg}$ and/or DBP $\geq 90 \mathrm{mmHg}$;

- Body mass: underweight $<18.5 \mathrm{~kg} / \mathrm{m}^{2}$, normal body mass $18.5-24.99 \mathrm{~kg} / \mathrm{m}^{2}$, overweight $25-29.9 \mathrm{~kg} / \mathrm{m}^{2}$, obesity $\geq 30 \mathrm{~kg} / \mathrm{m}^{2}$, and abdominal obesity: waist 
circumference $>94 \mathrm{~cm}$ for men and $>80 \mathrm{~cm}$ for women;

- Level of glycemia: fasting glucose $\geq 126 \mathrm{mg} / \mathrm{dl}$ (diabetes), and fasting glucose of 100-125 $\mathrm{mg} / \mathrm{dl}$ (prediabetes);

- Lipid profile: total cholesterol $<190 \mathrm{mg} / \mathrm{dl}$, triglycerides $<150 \mathrm{mg} / \mathrm{dl}$; LDL-C $\leq 115 \mathrm{mg} / \mathrm{dl}$, HDL-C $\geq 40$ $\mathrm{mg} / \mathrm{dl}$ for men and $\geq 45 \mathrm{mg} / \mathrm{dl}$ for women;

- Smoking: >1 cigarette per day;

- Burdened family history: stroke and/or a myocardial infarction - mother before the age of 60 years, father before the age of 55 years;

The risk of death for cardiovascular reasons in ten years according to the SCORE was as follows: low $<1 \%$, moderate $1-4 \%$, high $5-9 \%$, and very high $\geq 10 \%$.

\section{Statistical Analysis}

Statistical analysis was performed using Statistica v.13.3 (TIBCO $^{\circledR}$ Statistica, 2018, Palo Alto, USA). All variables were first analyzed using descriptive statistics. Depending on the type of the measurement scale on which individual variables were expressed, various measures of descriptive statistics were determined. In the case of quantitative variables, dispersion measures (standard deviation, quartile range, coefficient of variation) were calculated. However, the structure measure (frequency) was determined for variables described on the nominal or ordinal scale. ${ }^{8}$ Based on the central limit theorem, which states that in large populations $(\mathrm{N}>100)$ quantitative variables have a distribution close to normal, we decided to use parametric statistics in their analysis. ${ }^{9}$ The results obtained for the same study sample over a five-year period (2012/13 vs 2017/2018) were compared using Student's $t$-test for independent samples. The size of the effect for the observed difference between the samples was estimated using Cohn's coefficient. ${ }^{10}$ It was assumed that the size of the difference was: small ( $d: 0.10-0.30)$, medium $(d: 0.31-$ $0.50)$, large $(d>0.50)$. All measures of effect size had a $95 \%$ confidence interval. ${ }^{11}$

A nonparametric approach, based on contingency tables and Pearson's chi-square test, was used to analyze non-metric variables. In the case of dichotomous variables, which only had two variants, the odds ratio (OR) was additionally determined. A $95 \%$ confidence interval was calculated for all effect size measures. The analysis of the change in the values of variables for the repeated measurement was based on parametric statistics (Student's $t$-test for dependent samples) or nonparametric statistics (Wilcoxon matched-pairs test) depending on the type of a measuring scale. The effect size measures were used for the tests: Cohn's d coefficient, the eta-squared coefficient $\left(\eta^{2}\right)$, and $\mathrm{OR},{ }^{12}$ respectively. A $95 \%$ confidence interval was calculated for all effect size measures. The assessment of the impact of two selected factors (sex and an age bracket) on the change in the average values of selected parameters over a five-year observation period was carried out using the multivariate analysis of variance (MANOVA). In the case of non-metric variables, the change in the selected parameters over a five-year observation period was analyzed by means of the CochranMantel-Haenszel test. The effect size measures were determined: $\eta^{2}$ and the Mantel-Haenszel relative risk $\left(\mathrm{R}_{\mathrm{MH}}\right) .{ }^{13}$ A $95 \%$ confidence interval was calculated for all effect size measures.

\section{Results}

The study sample consisted of 294 individuals at the age of 35-55 years, the majority of whom were women $(65.3 \%)$. Based on the collected data on the prevalence of selected cardiovascular disease risk factors in the study population, statistically significant differences in waist circumference were observed over a five-year interval. The results of the repeated measurement of waist circumference indicated that after five years more respondents were classified as having visceral obesity. In the re-examination, the odds of obesity were about 2.5 times greater $(\mathrm{OR}=2.56)$. Although statistically significant differences in the levels of HDL-C and TG were not observed, it can be noticed that the above-mentioned lipid parameters deteriorated after five years (Table 1).

Analysis of the data demonstrated statistically significant differences $(p<0.05)$ in the BMI values and the SCORE results obtained in the same respondents over a five-year time interval. The results of the repeated BMI measurement show that after five years more respondents were classified as overweight and obese compared with the first measurement ( $\left.p=0.000 ; \eta^{2}=0.056\right)$. The results of the repeated SCORE measurement indicate that after five years the SCORE values significantly increased compared with the first measurement $\left(p=0.000 ; \eta^{2}=0.588\right)$ (Table 2).

Statistically significant differences $(p<0.05)$ were also found between the first and the second measurements of arm circumference, waist circumference, BMI, diastolic blood pressure, heart rate, and TG (Table 3). 
Table I The Odds Radio of Variables Over a Five-Year Time Interval

\begin{tabular}{|c|c|c|c|c|c|c|c|c|}
\hline \multicolumn{2}{|l|}{ Variables } & \multicolumn{2}{|c|}{$2012 / 2013$} & \multicolumn{2}{|c|}{$2017 / 2018$} & \multirow{3}{*}{$\frac{\chi^{2}}{2.370}$} & \multirow{3}{*}{$\begin{array}{l}\mathbf{P *} \\
0.124\end{array}$} & \multirow{3}{*}{$\begin{array}{l}\text { OR }(95 \% \mathrm{CI}) \\
2.00(0.85 ; 5.05)\end{array}$} \\
\hline & & \multirow{2}{*}{$\begin{array}{l}\mathbf{n} \\
264 \\
30\end{array}$} & \multirow{2}{*}{$\begin{array}{l}\% \\
89.8 \\
10.2\end{array}$} & \multirow{2}{*}{$\begin{array}{l}\mathbf{n} \\
255 \\
39\end{array}$} & \multirow{2}{*}{$\begin{array}{l}\% \\
86.7 \\
13.3\end{array}$} & & & \\
\hline Genetics & $\begin{array}{l}\text { Negative } \\
\text { Positive }\end{array}$ & & & & & & & \\
\hline SBP $[\mathrm{mmHg}]$ & $\begin{array}{l}\text { Normal } \\
\text { Elevated }\end{array}$ & $\begin{array}{l}281 \\
13\end{array}$ & $\begin{array}{l}95.6 \\
4.4\end{array}$ & $\begin{array}{l}281 \\
13\end{array}$ & $\begin{array}{l}95.6 \\
4.4\end{array}$ & 0.050 & 0.823 & $1.00(0.37 ; 2.68)$ \\
\hline $\mathrm{DBP}[\mathrm{mmHg}]$ & $\begin{array}{l}\text { Normal } \\
\text { Elevated }\end{array}$ & $\begin{array}{l}289 \\
5\end{array}$ & $\begin{array}{l}98.3 \\
1.7\end{array}$ & $\begin{array}{l}284 \\
10\end{array}$ & $\begin{array}{l}96.6 \\
3.4\end{array}$ & 1.455 & 0.228 & $2.67(0.64 ; 15.6 I)$ \\
\hline Waist circumference $[\mathrm{cm}]$ & $\begin{array}{l}\text { Normal } \\
\text { Elevated }\end{array}$ & $\begin{array}{l}165 \\
129\end{array}$ & $\begin{array}{l}56.1 \\
43.9\end{array}$ & $\begin{array}{l}137 \\
157\end{array}$ & $\begin{array}{l}46.6 \\
53.4\end{array}$ & 11.391 & 0.001 & $2.56(1.45 ; 4.68)$ \\
\hline Glycemia [mg\%] & $\begin{array}{l}\leq 99 \\
>100\end{array}$ & $\begin{array}{l}260 \\
34\end{array}$ & $\begin{array}{l}88.4 \\
11.6\end{array}$ & $\begin{array}{l}265 \\
29\end{array}$ & $\begin{array}{l}90.1 \\
9.9\end{array}$ & 0.432 & 0.511 & $0.76(0.37 ; 1.53)$ \\
\hline HDL-C [mg/dl] & $\begin{array}{l}\text { Normal } \\
\text { Decreased }\end{array}$ & $\begin{array}{l}280 \\
14\end{array}$ & $\begin{array}{l}95.2 \\
4.8\end{array}$ & $\begin{array}{l}272 \\
22\end{array}$ & $\begin{array}{l}92.5 \\
7.5\end{array}$ & 1.750 & 0.186 & $\mathrm{I} .80(0.79 ; 4.37)$ \\
\hline TG [mg/dl] & $\begin{array}{l}\leq 150 \\
>150\end{array}$ & $\begin{array}{l}265 \\
29\end{array}$ & $\begin{array}{l}90.1 \\
9.9\end{array}$ & $\begin{array}{l}259 \\
35\end{array}$ & $\begin{array}{l}88.1 \\
11.9\end{array}$ & 0.625 & 0.429 & $1.35(0.69 ; 2.70)$ \\
\hline
\end{tabular}

Notes: $\chi^{2}$-chi-square test, $\mathrm{p}^{*}$-statistical significance.

Abbreviations: OR, odds ratio; Genetics, family burden of cardiovascular disease (CVD); SBP, systolic blood pressure; DBP, diastolic blood pressure; HDL-C, high-density lipoprotein cholesterol; TG, triglycerides.

\section{Comparative Analysis with Regard to Sex and an Age Bracket}

The study involved comparative analysis of selected sociodemographic variables (sex and age) and risk factors for a cardiovascular incident. Based on the collected data, it has been shown that sex is an important factor differentiating the results of the repeated BMI and total cholesterol measurements $(\mathrm{p}<0.05)$. The mean increase in the BMI values for men was significantly lower than for women (men: 26.1 vs 26.46; women: 24.07 vs 25.16). The mean cholesterol levels in men decreased (men: $213.23 \mathrm{mg} / \mathrm{dl}$ vs $210.00 \mathrm{mg} / \mathrm{dl}$ ), while in women they rose (women: $196.78 \mathrm{mg} / \mathrm{dl}$ vs $200.82 \mathrm{mg} / \mathrm{dl}$ ). There was no significant interaction $(\mathrm{p}>0.05)$ between sex and age in the modelling of changes in the mean BMI value (Figure 1) and the mean cholesterol level (Figure 2) in the repeated measurements.

Furthermore, it was shown that sex and age were not significant factors differentiating the results of arm circumference, waist circumference, systolic blood pressure, diastolic blood pressure, and heart rate measurements repeated after five years $(\mathrm{p}>0.05)$. There were also no significant differences in the results of the repeated measurements of glycemia, LDL-C, HDL-C, or TG.

\section{Comparative Analysis with Regard to Sex for Dichotomous Non-Metric Variables}

Statistical analysis demonstrated that the risk of visceral obesity was statistically significantly higher after five years $(p=0.032)$. At both measurements, it was higher for men than for women $\left(\mathrm{R}_{\mathrm{HM}}=1.47\right)$. As for the rest of dichotomous non-metric variables (genetic factors, systolic blood pressure, diastolic blood pressure, glycemia, HDL-C, and TG) no statistically significant differences between the measurements for particular sexes were observed $(p>0.05)$ (Table 4).

\section{Discussion}

It is noteworthy that our research is one of the few studies assessing the risk of a cardiovascular incident in the same subjects over a five-year interval. In addition, it indicates a significant increase in the risk of death from cardiovascular disease. In their meta-analysis of data from 30 countries conducted for the adult population, Kearney et al demonstrated a rise in the incidence of hypertension. They estimated that the percentage of people with hypertension will increase from $26.4 \%$ to $29.2 \% .{ }^{15}$ The NATPOL research also indicated an increase in the prevalence of hypertension from $30 \%$ to $32 \%$ within nine years. ${ }^{16}$ Different results were obtained in the WOBASZ 
Table 2 Comparison of the Variables Over a Five-Year Time Interval

\begin{tabular}{|c|c|c|c|c|c|c|c|c|}
\hline \multicolumn{2}{|l|}{ Variables } & \multicolumn{2}{|c|}{$2012 / 2013$} & \multicolumn{2}{|c|}{$2017 / 2018$} & \multirow[t]{2}{*}{$\mathbf{Z}$} & \multirow[t]{2}{*}{$\mathbf{P} *$} & \multirow[t]{2}{*}{$H^{2}$} \\
\hline & & $\mathbf{n}$ & $\%$ & $\mathbf{n}$ & $\%$ & & & \\
\hline \multirow[t]{3}{*}{ Smoking } & Never smoked & 172 & 58.5 & 176 & 59.9 & 0.797 & 0.425 & 0.002 \\
\hline & Gave up smoking & 68 & 23.1 & 66 & 22.4 & & & \\
\hline & Smoke & 54 & 18.4 & 52 & 17.7 & & & \\
\hline \multirow[t]{8}{*}{ Physical activity over 30 minutes a day (per week) } & No activity & 155 & 52.7 & 133 & 45.2 & 1.642 & 0.101 & 0.009 \\
\hline & I time & 39 & 13.3 & 29 & 9.9 & & & \\
\hline & 2 times & 28 & 9.5 & 54 & 18.4 & & & \\
\hline & 3 times & 24 & 8.2 & 33 & 11.2 & & & \\
\hline & 4 times & 13 & 4.4 & 8 & 2.7 & & & \\
\hline & 5 times & 19 & 6.5 & 22 & 7.5 & & & \\
\hline & 6 times & 2 & 0.7 & 4 & 1.4 & & & \\
\hline & 7 times & 14 & 4.8 & II & 3.7 & & & \\
\hline \multirow[t]{3}{*}{ BMI } & Normal & 165 & 56.1 & 139 & 47.3 & 4.041 & 0.000 & 0.056 \\
\hline & Overweight & 105 & 35.7 & 117 & 39.8 & & & \\
\hline & Obesity & 24 & 8.2 & 38 & 12.9 & & & \\
\hline \multirow[t]{3}{*}{ TC [mg/dl] } & $\leq 190$ & 114 & 38.8 & 107 & 36.4 & 0.492 & 0.623 & 0.001 \\
\hline & $191-250$ & 155 & 52.7 & 163 & 55.4 & & & \\
\hline & $>250$ & 25 & 8.5 & 24 & 8.2 & & & \\
\hline \multirow[t]{3}{*}{ LDL-C [mg/dl] } & $\leq 115$ & 135 & 45.9 & 152 & 51.7 & 0.913 & 0.361 & 0.003 \\
\hline & $116-130$ & 63 & 21.4 & 44 & 15.0 & & & \\
\hline & $>130$ & 96 & 32.7 & 98 & 33.3 & & & \\
\hline \multirow[t]{6}{*}{ SCORE } & $<1 \%$ & 178 & 60.5 & 93 & 31.6 & 13.144 & 0.000 & 0.588 \\
\hline & $1 \%$ & 79 & 26.9 & 38 & 12.9 & & & \\
\hline & $2 \%$ & 18 & 6.1 & 128 & 43.5 & & & \\
\hline & $3-4 \%$ & 17 & 5.8 & 21 & 7.1 & & & \\
\hline & 5-9\% & 2 & 0.7 & 12 & 4.1 & & & \\
\hline & $10-14 \%$ & 0 & 0.0 & 2 & 0.7 & & & \\
\hline
\end{tabular}

Notes: Z-Wilcoxon matched-pairs test, $\mathrm{p}^{*}$-statistical significance, $\eta^{2}$-effect size for the difference between the measurements.

Abbreviations: BMI, body mass index; TC, total cholesterol; LDL-C, low-density lipoprotein cholesterol; SCORE, Systematic Coronary Risk Evaluation.

Table 3 Comparison of the Average Values from Measurements Performed Over a Five-Year Time Interval

\begin{tabular}{|c|c|c|c|c|c|c|c|}
\hline \multirow[t]{2}{*}{ Variables } & \multicolumn{2}{|c|}{$2012 / 2013$} & \multicolumn{2}{|c|}{$2017 / 2018$} & \multirow[t]{2}{*}{$\mathbf{t}$} & \multirow[t]{2}{*}{$\mathbf{p}^{*}$} & \multirow[t]{2}{*}{ d $(95 \% \mathrm{Cl})$} \\
\hline & $\mathbf{M}$ & SD & $\mathbf{M}$ & SD & & & \\
\hline Arm circumference $[\mathrm{cm}]$ & 28.51 & 3.77 & 28.97 & 3.96 & -2.559 & 0.011 & $0.12(0.04 ; 0.28)$ \\
\hline Waist circumference $[\mathrm{cm}]$ & 83.64 & 11.43 & 86.39 & 12.27 & -6.093 & 0.000 & $0.24(0.08 ; 0.40)$ \\
\hline BMI & 24.80 & 3.83 & 25.61 & 4.30 & -5.252 & 0.000 & $0.2 I(0.05 ; 0.37)$ \\
\hline $\mathrm{SBP}[\mathrm{mmHg}][\mathrm{mm}]$ & 114.67 & 11.36 & 115.24 & 12.85 & -0.682 & 0.496 & $0.05(-0.11 ; 0.21)$ \\
\hline $\mathrm{DBP}[\mathrm{mmHg}]$ & 72.95 & 7.20 & 74.35 & 7.42 & -2.802 & 0.005 & $0.19(0.03 ; 0.36)$ \\
\hline Heart rate $[\mathrm{bpm}]$ & 72.85 & 7.14 & 71.41 & 5.81 & 3.614 & 0.000 & $0.20(0.04 ; 0.36)$ \\
\hline Glycemia [mg\%] & 90.05 & 8.18 & 89.75 & 8.72 & 0.598 & 0.550 & $0.04(-0.13 ; 0.20)$ \\
\hline $\mathrm{TC}[\mathrm{mg} / \mathrm{dl}]$ & 202.49 & 35.04 & 204.00 & 34.89 & -0.830 & 0.407 & $0.04(-0.20 ; 0.21)$ \\
\hline LDL-C [mg/dl] & 118.95 & 31.63 & 117.37 & 32.76 & 0.834 & 0.405 & $0.05(-0.11 ; 0.21)$ \\
\hline HDL-C [mg/dl] & 64.78 & 15.17 & 66.32 & 18.00 & -1.833 & 0.068 & $0.10(-0.06 ; 0.26)$ \\
\hline TG [mg/dl] & 93.86 & 47.21 & 102.45 & 58.41 & -3.198 & 0.002 & $0.18(0.02 ; 0.34)$ \\
\hline
\end{tabular}

Notes: $\mathrm{p}^{*}-$ Student's $t$-test, $d$-Cohen's coefficient (effect size).

Abbreviations: M, mean; SD, standard deviation; BMI, body mass index; SBP, systolic blood pressure; DBP, diastolic blood pressure; TC, total cholesterol; LDL-C, lowdensity lipoprotein cholesterol; HDL-C, high-density lipoprotein cholesterol; TG, triglycerides. 


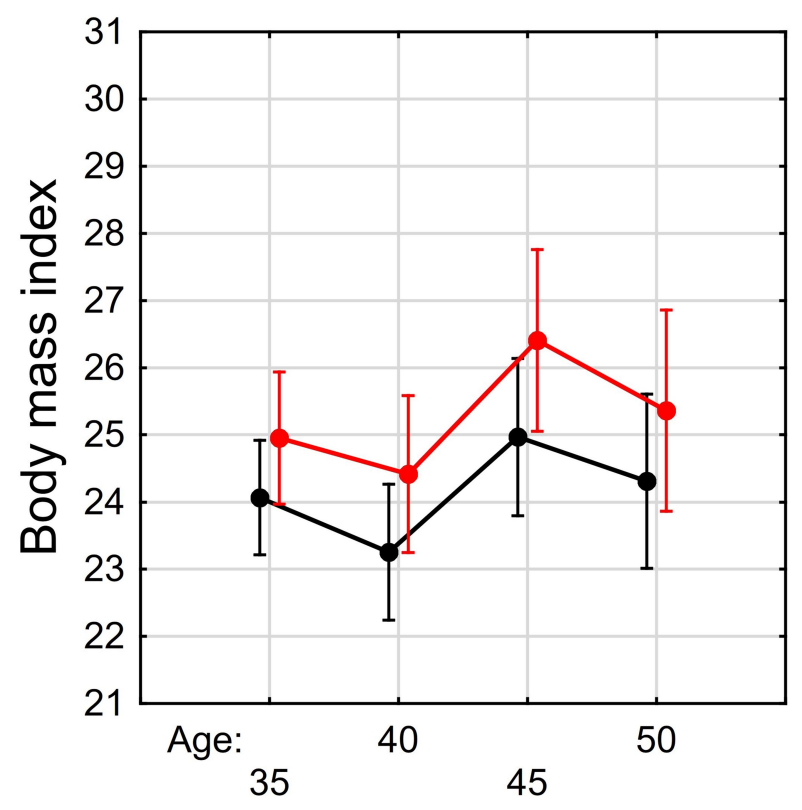

Female

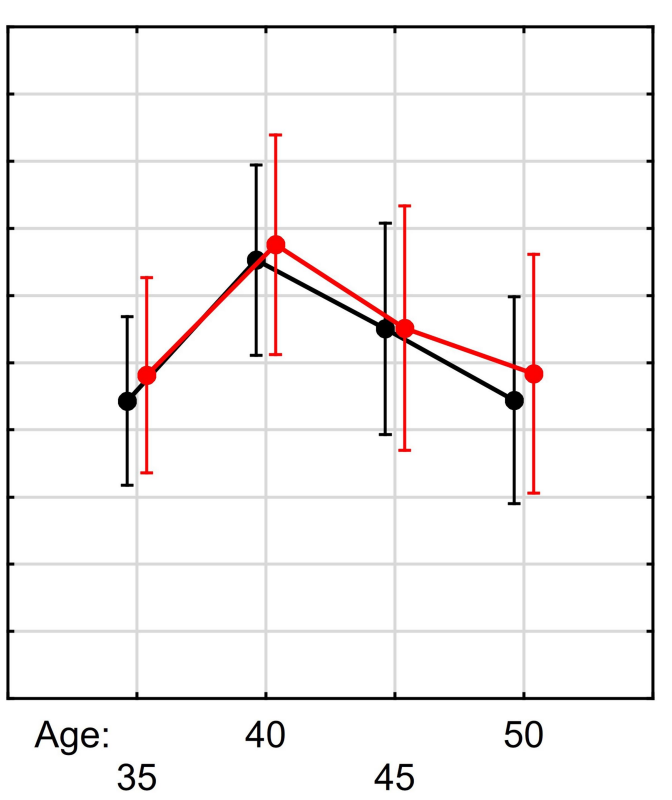

Male
\$2012/2013

$\mp 2017 / 2018$

Figure I Model of changes in body mass index (BMI) including sex and age group in the five-year observation of the subjects.

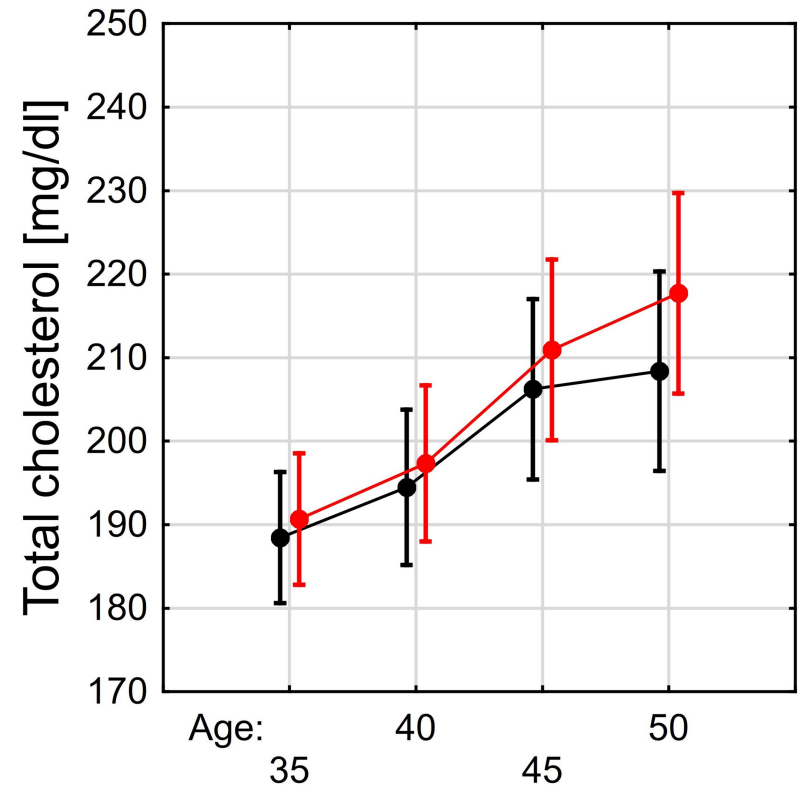

Female

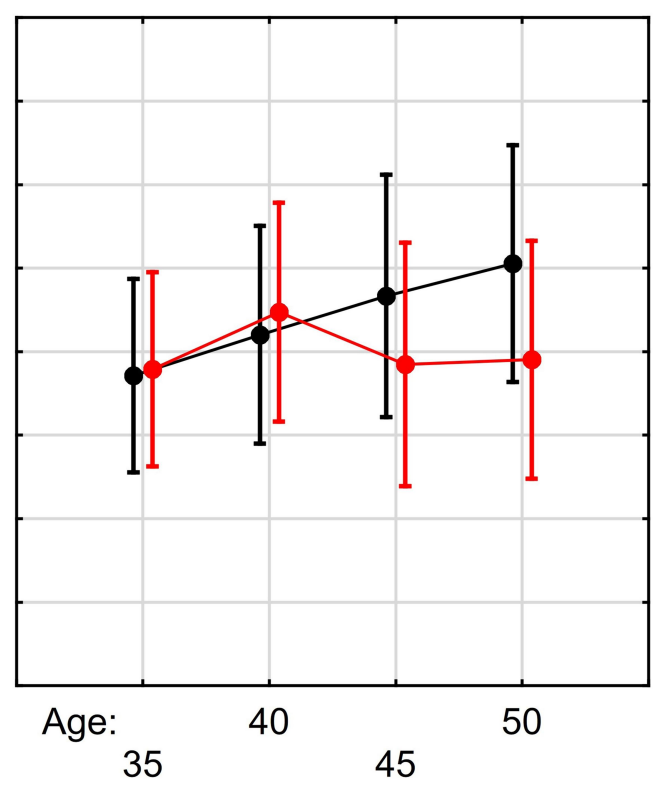

Male
2012/2013

2017/2018

Figure 2 Model of changes in mean total cholesterol concentration (TC) including sex and age group in the five-year observation of the subjects.

I (2003-2005) and WOBASZ II (2013-2014) studies, in which the percentage of people with elevated blood pressure decreased. This was attributed to the fact that more patients were receiving effective antihypertensive treatment and blood pressure was better controlled. The data of the National Health Fund Prevention Monitoring
System, developed by M. Kwaśniewska and W. Drygas, revealed a positive downward trend in the prevalence of hypertension in the years 2008, 2010, 2013 and 2014 $\left(15 \%, 11 \%, 8.3 \%\right.$, and $7.5 \%$, respectively). ${ }^{17}$

Cardiovascular diseases are diseases of civilization, which are the most common cause of death on a global 
Table 4 Changes in the Selected Factors with Regard to Sex Over a Five-Year Observation Period

\begin{tabular}{|c|c|c|c|c|c|c|c|c|}
\hline \multirow[t]{2}{*}{ Variables } & & \multirow[t]{2}{*}{ Sex } & \multicolumn{2}{|c|}{$2012 / 2013$} & \multicolumn{2}{|c|}{$2017 / 2018$} & \multirow[t]{2}{*}{$\chi^{2}$} & \multirow[t]{2}{*}{$\mathbf{p}^{*}$} \\
\hline & & & $\mathbf{n}$ & $\%$ & $\mathbf{n}$ & $\%$ & & \\
\hline \multirow[t]{4}{*}{ Genetics } & Negative & Women & 170 & 88.5 & 161 & 83.9 & \multirow[t]{4}{*}{0.808} & \multirow[t]{4}{*}{0.369} \\
\hline & Positive & & 22 & 11.5 & 31 & 16.1 & & \\
\hline & Negative & Men & 94 & 92.2 & 94 & 92.2 & & \\
\hline & Positive & & 8 & 7.8 & 8 & 7.8 & & \\
\hline \multirow[t]{4}{*}{ SBP $[\mathrm{mmHg}]$} & Normal & Women & 185 & 96.4 & 190 & 99.0 & \multirow[t]{4}{*}{0.163} & \multirow[t]{4}{*}{0.686} \\
\hline & Elevated & & 7 & 3.6 & 2 & 1.0 & & \\
\hline & Normal & Men & 96 & 94.1 & 91 & 89.2 & & \\
\hline & Elevated & & 6 & 5.9 & 11 & 10.8 & & \\
\hline \multirow[t]{4}{*}{$\mathrm{DBP}[\mathrm{mmHg}]$} & Normal & Women & 189 & 98.4 & 190 & 99.0 & \multirow[t]{4}{*}{0.621} & \multirow[t]{4}{*}{0.431} \\
\hline & Elevated & & 3 & 1.6 & 2 & 1.0 & & \\
\hline & Normal & Men & 100 & 98.0 & 94 & 92.2 & & \\
\hline & Elevated & & 2 & 2.0 & 8 & 7.8 & & \\
\hline \multirow[t]{4}{*}{ Waist circumference $[\mathrm{cm}]$} & Normal & Women & 108 & 56.3 & 91 & 47.4 & \multirow[t]{4}{*}{4.587} & \multirow[t]{4}{*}{0.032} \\
\hline & Elevated & & 84 & 43.8 & 101 & 52.6 & & \\
\hline & Normal & Men & 57 & 55.9 & 46 & 45.1 & & \\
\hline & Elevated & & 45 & 44.1 & 56 & 54.9 & & \\
\hline \multirow[t]{4}{*}{ Glycemia [mg\%] } & $\leq 99$ & Women & 173 & 90.1 & 179 & 93.2 & \multirow[t]{4}{*}{0.878} & \multirow[t]{4}{*}{0.349} \\
\hline & $>100$ & & 19 & 9.9 & 13 & 6.8 & & \\
\hline & $\leq 99$ & Men & 87 & 85.3 & 86 & 84.3 & & \\
\hline & $>100$ & & 15 & 14.7 & 16 & 15.7 & & \\
\hline \multirow[t]{4}{*}{ HDL-C [mg/dl] } & Normal & Women & 184 & 95.8 & 180 & 93.8 & \multirow[t]{4}{*}{1.064} & \multirow[t]{4}{*}{0.302} \\
\hline & Decreased & & 8 & 4.2 & 12 & 6.3 & & \\
\hline & Normal & Men & 96 & 94.1 & 92 & 90.2 & & \\
\hline & Decreased & & 6 & 5.9 & 10 & 9.8 & & \\
\hline \multirow[t]{4}{*}{ TG [mg/dl] } & $\leq 150$ & Women & 186 & 96.9 & 180 & 93.8 & \multirow[t]{4}{*}{0.302} & \multirow[t]{4}{*}{0.583} \\
\hline & $>150$ & & 6 & 3.1 & 12 & 6.3 & & \\
\hline & $\leq 150$ & Men & 79 & 77.5 & 79 & 77.5 & & \\
\hline & $>150$ & & 23 & 22.5 & 23 & 22.5 & & \\
\hline
\end{tabular}

Notes: $\chi^{2}$-chi-square test, $\mathrm{p}^{*}$-statistical significance.

Abbreviations: Genetics, family burden of cardiovascular disease (CVD); SBP, systolic blood pressure; DBP, diastolic blood pressure; HDL, C-high-density lipoprotein cholesterol; TG, triglycerides.

scale, which means that 17.9 million people die every year from them. ${ }^{14}$ Despite the fact that women die more often due to cardiovascular disease, which is related to the older structure of their age, cardiovascular diseases pose a greater threat to men's lives. ${ }^{18}$ In our study, men were at a greater risk of cardiovascular disease than women. Statistical analysis demonstrated that the risk of visceral obesity was statistically significantly higher for men than for women after five years. Our previous study confirmed that, according to the SCORE results, men were more often diagnosed with moderate, high, and very high risk of a cardiovascular incident ending in death than women. ${ }^{19}$

A breakthrough in preventive cardiology research was the Framingham Heart Study (FHS), which was the first to identify factors predisposing to cardiovascular disease. The study was started in 1948-1953 (original cohort), then continued with the children of the original cohort (offspring cohort), and ended with the children of the offspring cohort (the third FHS generation-2002-2005). The average age of the FHS third-generation group was similar to that of the first and second generations. The 
smoking rates, blood pressure, and total cholesterol were significantly lower in the third generation cohort than in the previous years. At the same time, the percentage of people receiving antihypertensive treatment was definitely higher among the respondents from 2002-2005. The average BMI increased over three generations of the study participants, especially among men. About one-fourth of men and one-fifth of women in the third generation cohort were obese. $^{20-23}$

Similar results were reported by Jayedi et $\mathrm{al}^{24}$ who conducted a meta-analysis of eleven cohort studies with 505.802 participants, of whom 21.316 were assessed in terms of weight gain $(\mathrm{kg})$ in adulthood. These studies confirmed that significant weight gain contributes to a higher risk of death from a cardiovascular incident. On the other hand, the meta-analysis of 28 studies carried out by Aune et $\mathrm{al}^{25}$ emphasizes that overweight and obesity (especially visceral) increases the risk of heart failure.

Our study confirmed the existence of a relationship between obesity and an elevated risk of developing cardiovascular disease. It was also observed that the incidence of obesity, including abdominal obesity, among the same respondents examined over a 5-year interval, increased twice. Men were most likely to have visceral obesity in the re-examination. Moreover, according to the SCORE results, they were more often classified as having a moderate, high, and very high risk of a fatal cardiovascular incident within ten years compared to women. A review of the literature indicates that obesity is a serious problem worldwide, since over the past 35 years in Europe alone, the percentage of people diagnosed with overweight has increased from $48 \%$ in 1980 to $59.6 \%$ in 2015 , and a similar trend in the incidence of obesity has been observed ( $14.5 \%$ in 1980 vs. $22.9 \%$ in 2015 ). According to the data presented by Andolfi et $\mathrm{al}^{26}$ currently in the US obese people constitute $33 \%$ of the population, and it is estimated that this percentage will increase to $50 \%$ in 2030 . The Polish Multi-centre National Population Health Examination Survey WOBASZ I project showed that in the population aged $20-74,40.4 \%$ of men and $27.9 \%$ of women were overweight, $20.6 \%$ of men and $20.2 \%$ of women were obese. Analysis of the data from the 2011 NATPOL survey revealed that obesity was more common in men than in women $(23.6 \%$ vs $19.7 \%)$. The mean BMI values were $27.2 \mathrm{~kg} / \mathrm{m}^{2}$ for men and $26.1 \mathrm{~kg} / \mathrm{m}^{2}$ for women. ${ }^{16}$ In the study of Kwaśniewska and Drygas, the percentages of overweight women were $33 \%$ in $2008,32 \%$ in $2010,31.3 \%$ in 2013 , and $31.3 \%$ in 2014 , and were higher than in our own research. The results in the male group were $47.7 \%, 48 \%, 49.3 \%$, and $48.8 \%$, respectively, and were similar to our findings. ${ }^{17}$

Exposure to tobacco smoke is one of the modifiable risk factors that has a large impact on global mortality. Smoking-related mortality is associated with a higher incidence of atherosclerotic cardiovascular disease, lung cancer, and chronic obstructive pulmonary disease. ${ }^{27,28}$ Study by Mozos et al shows sex differences in arterial stiffness and arterial age in smokers. It suggests that smoking packyears (SPY) is significantly associated with an increased arterial stiffness, regardless of sex and with an increased systolic blood pressure in the aorta in female smokers. ${ }^{29}$ Recent data indicate that, worldwide, cigarette smoking is more common among men (25\% of men vs. $5.4 \%$ of women). ${ }^{30}$ The results of the WOBASZ I (2003-2005) showed the prevalence of cigarette smoking at the level of $31 \%$. This risk factor was more common in men than in women $(39.55 \%$ vs. $23.4 \%)$. In the second edition of the survey, the WOBASZ II (2013-2014), the percentage of smokers decreased to $25 \%$ compared to the Health, Alcohol and Psychosocial factors in Eastern Europe (HAPIEE) study-39.2\%. Taking into account sex, both a greater prevalence and a greater decline in the prevalence of smoking were observed in men. ${ }^{17}$ Our own research has shown that the vast majority of respondents have never smoked cigarettes. Analysis of data from the years 2012/ 2013 and 2017/2018 revealed that significantly fewer respondents smoked in 2017/2018 and perhaps the collected data are part of the positive downward trend in cigarette smoking in Poland. In the analysis of the respondents examined twice within five years, it was observed that two people quit smoking. However, it is puzzling that more people in the second study declared that they had never smoked. This can be explained by a mistake or dishonesty of the respondents' answers.

Tomasik et al claim that the minimum health-promoting physical effort should be 150 minutes of moderate physical activity or 75 minutes of vigorous exercise per week. In both cases, aerobic exercises should be performed. Nevertheless, it is recommended to perform physical activity at an optimal level, resulting in an extension of up to 300 minutes for moderate exercise and up to 150 minutes for vigorous exercise. ${ }^{31}$ In our study, most of the respondents stated that they exercised less than three times a week. Murphy et al reported a much greater percentage of respondents (41-55\%) who were physically active for at least 150 minutes a week. The analysis of physical activity 
by sex showed that a greater percentage of men played sport than women, and the percentages in the age group of $31-40$ years were $58 \%$ vs $52 \%$, and in the age group of 41-60 years were $43 \%$ vs $55 \%$, respectively. ${ }^{32}$ Nationwide analyses of the CVD Prevention Program indicate that in 2013 and 2014 low physical activity was noted in less than $80 \%$ of men and $81.7-80.4 \%$ of women. ${ }^{17}$

Family history is a nonmodifiable cardiovascular risk factor; however, it is not impossible for new cardiovascular events to occur in different families in a five-year interval. In our research, statistically significant differences in family history were not observed. No statistically significant differences in genetic factors between men and women were observed. Nevertheless, it is worth mentioning that the first attempts to link the incidence of coronary artery disease in patients whose parents had a heart attack before the age of 50 took place as early as 1961. Shannon et al described an increase in the incidence of ischemic heart disease in people whose families had premature cardiovascular disease manifested by a heart attack. ${ }^{33}$ The INTERHEART study (2011) also confirmed the correlation between a positive family history and an increased risk of heart attack in children. ${ }^{34}$

The results of this study are important for clinical practice and policy makers, as they allow us to learn about some of the behavioral patterns in the context of the development of cardiovascular diseases that make up the modern lifestyle of the inhabitants of West Pomeranian Province, Poland. For this reason, they may constitute the basis for the development of further preventive programs in line with the objectives of the National Health Program adopted in Poland for 2016-2020.

\section{Limitations}

- The Cardiovascular Disease Prevention Program has been implemented in Poland by the National Health Fund to reduce the incidence of and mortality due to cardiovascular disease by early detection and reduction of cardiovascular disease risk factors. The burden of CVD increases with age, including higher incidence, case-fatality, longer-term mortality, and prevalence. Thus, the restricted age range in SCORE $(<65$ years old) is a major limitation of our research.

- The SCORE system has some limitations in assessing the risk of cardiovascular events. For example, it does not include the following risk factors for CVD: arterial stiffness and pulse wave analysis, carotid intimamedia thickness, flow-mediated dilatation of the brachial artery, coronary artery calcium score, Ankle Brachial Index, high sensitivity C-reactive protein, advanced glycation end-products, markers of oxidative stress (including Matrix Metalloproteinases), and B-type natriuretic peptide. We should include these risk factors for CVD in our future research.

- In our research, we only took into consideration the general information on physical activity and smoking habits provided by the participants. We were also concerned that participants might change the answer after five years.

- The limitation of our research is also the fact of recruiting the same participants to check the severity of changes in cardiovascular risk factors over a fiveyear interval.

\section{Conclusion}

- In the group of patients examined twice over five years, the incidence of obesity, including abdominal obesity, significantly increased. The highest probability of abdominal obesity in the re-examination was for men.

- Five years after the last examination, the risk of a cardiovascular incident significantly increased. The participants had higher values of such parameters as: arm circumference, waist circumference, BMI, diastolic blood pressure, heart rate, and triglycerides.

\section{Author Contributions}

All authors made substantial contributions to conception and design, acquisition of data, or analysis and interpretation of data; took part in drafting the article or revising it critically for important intellectual content; agreed to submit to the current journal; gave final approval of the version to be published; and agree to be accountable for all aspects of the work.

\section{Funding}

This research received no external funding.

\section{Disclosure}

The authors report no conflicts of interest in this work.

\section{References}

1. Jayedi A, Rashidy-pour A, Khorshidi M, et al. Body mass index, abdominal adiposity, weight gain and risk of developing hypertension: a systematic review and dose-response metaanalysis of more than 2.3 million participants. Obes Rev. 2018;19:654-667. doi:10.1111/ obr. 12656 
2. European Guidelines on cardiovascular disease prevention in clinical practice (version 2012). The fifth joint task force of the European Society of Cardiology and other societies on cardiovascular disease prevention in clinical practice. Eur Heart J. 2012;98:941-946. doi:10.1093/eurheartj/ehs092

3. Conroy RM, Pyorala K, Fitzgerald A, et al. Estimation of ten-year risk of fatal cardiovascular disease in Europe: SCORE project. Eur Heart J. 2003;24:987-1003. doi:10.1016/S0195-668X(03)00114-3

4. Vikhireva O, Pająk A, Broda G, et al. SCORE performance in central and Eastern Europe and former Soviet Union: MONICA and HAPPIE results. Eur Heart J. 2014;35:571-577. doi:10.1093/eurheartj/eht189

5. DeFilippis AP, Yung R, Carrubba CJ, et al. An analysis of calibration and discrimination among multiple cardiovascular risk scores in a modern multiethnic cohort. Ann Intern Med. 2015;126:266-275. doi:10.7326/M14-1281

6. Polskie Towarzystwo Nadciśnienia Tętniczego. Zasady postępowania w nadciśnieniu tętniczym — 2019 rok. Wytyczne Polskiego Towarzystwa Nadciśnienia Tętniczego. Nadcisnienie Tetnicze $w$ Praktyce. 2019;5(1):1-86.

7. Pająk A, Szafraniec K, Janion M, et al. The impact of the Polish national programme of cardiovascular disease prevention on the quality of primary cardiovascular disease prevention in clinical practice. Kardiol Pol. 2010;68(12):1332-1341.

8. Stanisz A. Przystępny Kurs Statystyki w Oparciu o Program STATISTICA PL Na Przyktadach z Medycyny. StatSoft Polska; 1998.

9. Pólya G. Über den zentralen Grenzwertsatz der Wahrscheinlichkeitsrechnung und das Momentenproblem. Math Z. 1920;8(3):171-181. doi:10.1007/BF01206525

10. Fritz CO, Morris PE, Richler JJ. Effect size estimates: current use, calculations, and interpretation. J Ex Psychol Gen. 2012;141(1):2-18. doi: $10.1037 / \mathrm{a} 0024338$

11. Cohen J. Statistical Power Analysis for the Behavioral Sciences 2nd Edition. Hillsdale, NJ: Erlbaum; 1998.

12. Grimm LG, Yarnold PR, editors. Reading and Understanding Multivariate Statistics. Washington, DC, US: American Psychological Association; 1995.

13. Hall DB, Woolson RF, Clarke WR, et al. Cochran-mantel-Haenszel techniques: applications involving epidemiologic survey data. Handbook Stat. 1997;18:483-500. doi:10.1016/S0169-7161(00) 18018-6

14. Stol DM, Badenbroek IF, Hollander M, et al. Effectiveness of a stepwise cardiometabolic disease prevention program: results of a randomized controlled trial in primary care. Prev Med. 2020;132:105984. doi:10.1016/j.ypmed.2020.105984

15. Kearney PM, Whelton M, Reynolds K, et al. Global burden of hypertension: analysis of worldwide data. Lancet. 2005;365 (9455):217-223. doi:10.1016/S0140-6736(05)17741-1

16. Zdrojewski T, Solnica B, Cybulska B, et al. Prevalence of lipid abnormalities in Poland. The NATPOL 2011 survey. Kardiol Pol. 2016;74(3):213-223. doi:10.5603/KP.2016.0029

17. Kopeć G, Jankowski P, Pająk A, et al., editors. Epidemiologia $i$ Prewencja Chorób Układu Krążenia. Kraków, Poland: Medycyna praktyczna; 2015.

18. Mongraw-Chaffin ML, Peters SAE, Huxley RR, et al. The sex-specific association between BMI and coronary heart disease: a systematic review and meta-analysis of 95 cohorts with 1.2 million participants. Lancet Diabetes Endocrinol. 2015;3(6):437-449. doi:10.1016/S2213-8587(15)00086-8
19. Liput-Sikora A, Cybulska AM, Fabian W, et al. Cardiovascular risk distribution in a contemporary Polish collective. Int J Environ Res Public Health. 2020;17(9):3306. doi:10.3390/ijerph17093306

20. Spalansky GL, Corey D, Yang Q, et al. The third generation cohort of the National Heart, Lung and Blood Institute's Framingham Heart Study: design, recruitment and initial examination. Am J Epidemiol. 2007;165(11):1328-1335. doi:10.1093/aje/kwm021

21. O’Donnell C, Elosua R. Cardiovascular risk factors. Insights from Framingham Heart Study. Rev Esp Cardiol. 2008;61(3):299-310. doi:10.1016/s1885-5857(08)60118-8

22. Mahmood SS, Levy D, Vasan RS, et al. The Framingham Heart Study and the epidemiology of cardiovascular disease: a historical perspective. Lancet. 2014;383(9921):999-1008. doi:10.1016/S01406736(13)61752-3

23. Tsao CW, Vasan RS. Cohort profile: the Framingham Heart Study (FHS): overview of milestones in cardiovascular epidemiology. Int $J$ Epidemiol. 2015;44(6):1800-1813. doi:10.1093/ije/dyv337

24. Jayedi A, Rashidy-pour A, Soltani S, et al. Adult weight gain and the risk of cardiovascular disease: a systematic review and dose-response meta-analysis of prospective cohort studies. Eur J Clin Nutr. 2020;74 (9):1263-1275. doi:10.1038/s41430-020-0610-y

25. Aune D, Sen A, Norat T, et al. Body mass index, abdominal fatness, and heart failure incidence and mortality: a systematic review and doseresponse meta-analysis of prospective studies. Circulation. 2016;133 (7):639-649. doi:10.1161/CIRCULATIONAHA.115.016801

26. Andolfi C, Fisichella PM. Epidemiology of obesity and associated comorbidities. J Laparoendosc Adv Surg Tech A. 2018;28(8):919924. doi:10.1089/lap.2018.0380

27. Centers for Disease Control and Prevention (CDC). Smoking-attributable mortality, years of potential life lost, and productivity losses -United States, 2000-2004. MMWR Morb Mortal Wkly Rep. 2008;57 (45):1226-1228.

28. Centers for Disease Control and Prevention (CDC). Cigarette smoking among adults and trends in smoking cessation - United States, 2008. MMWR Morb Mortal Wkly Rep. 2009;58(44):1227-1232.

29. Mozos I, Maidana JP, Stoian D, Stehlik M. Gender differences of arterial stiffness and arterial age in smokers. Int J Environ Res Public Health. 2017;14(6):565. doi:10.3390/ijerph14060565

30. Reitsma MB, Fullman N, Ng M, GBD 2015 Tobacco Collaborators. Smoking prevalence and attributable disease burden in 195 countries and territories, 1990-2015: a systematic analysis from the Global Burden of Disease Study 2015. Lancet. 2017;389(10082):18851906. doi:10.1016/S0140-6736(17)30819-X

31. Tomasik R, Dębska M, Gołas A, et al. Krajowe Rekomendacje Prozdrowotnej Aktywności Fizycznej - Raport BadawczoAnalityczny. Katowice, Poland: Ministerstwo Sportu i Turystyki. Akademia Wychowania Fizycznego im. Jerzego Kukuczki w Katowicach; 2018.

32. Murphy MH, Donnelly P, Shibli S, et al. Physical activity, walking and leanness: an analysis of the Northern Ireland Sport and Physical Activity Survey (SAPAS). Prev Med. 2012;54(2):140-144. doi:10.1016/j.ypmed.2011.12.008

33. Shannon HM, Little A, Murphy EA. Studies of male survivors of myocardial infarction due to "essential" atherosclerosis. Can Med Assoc Med. 1961;84(10):519-530.

34. Chow CK, Islam S, Bautista L, et al. Parental history and myocardial infarction risk across the world. The INTERHEART Study. JACC. 2011;5(57):619-627. doi:10.1016/j.jacc.2010.07.054 


\section{Publish your work in this journal}

Clinical Interventions in Aging is an international, peer-reviewed journal focusing on evidence-based reports on the value or lack thereof of treatments intended to prevent or delay the onset of maladaptive correlates of aging in human beings. This journal is indexed on PubMed Central, MedLine, CAS, Scopus and the Elsevier
Bibliographic databases. The manuscript management system is completely online and includes a very quick and fair peer-review system, which is all easy to use. Visit http:/www.dovepress.com/ testimonials.php to read real quotes from published authors. 